\title{
INFORME PRELIMINAR SOBRE LA CERAMICA FUNERARIA DE AGUA TIBIA, TOTONICAPÁN, GUATEMALA
}

\author{
M. Josefa Iglesias Ponce de León \\ y Andrés Ciudad Rutz \\ Universidad Complutense, Madrid
}

Continuando el plan de investigaciones establecido por la Misión Científica Española en Guatemala en su IV temporada de campo, se ha excavado un pequeño terreno contiguo al trabajado en el verano de 1979, en el mismo sitio de Agua Tibia (M-5).

El sitio en cuestión (fig. 1), se localiza en un valle no muy ancho a $14^{\circ} 55^{\prime}$ de latitud Norte y $92^{\circ} 22^{\prime}$ de longitud Oeste, y dista $2.5 \mathrm{kms}$ de la ciudad de Totonicapán, a cuyo departamento pertenece. La zona excavada durante la temporada 1979-80 está a unos 200-225 mts del pequeño afluente que, con el nombre de Samalá primero y Pasutullé después, desemboca en el río Samalá, a corta distancia del pueblo de San Cristóbal Totonicapán.

Generalmente, tan sólo se aprovecha para el cultivo la estrecha franja aluvial y una pequeña porción contigua que transcurre a lo largo del valle y termina en la parte baja de los cerros que la delimitan, mientras que el resto está recubierto de pino rojo que, en la actualidad, ha disminuido bastante debido a los efectos devastadores del gorgojo - enfermedad muy extendida a lo largo del altiplano- y a la escasez y demanda creciente de leña y madera para muebles.

La zona excavada en esta segunda parte de la temporada se encuentra en milpa, cultivo que se ha iniciado hace año y medio, ya que el gorgojo obligó a la tala masiva de árboles en una enorme extensión del cerro en cuyas laderas se sitúa el asentamiento.

La apertura de tres calas de tamaño variable, tenía como finalidad aclarar una serie de cuestiones que se nos habían planteado en el transcurso de los trabajos efectuados en el pasado agosto de 1979; de ellas, quizás la más importante fue la de establecer la existencia de 


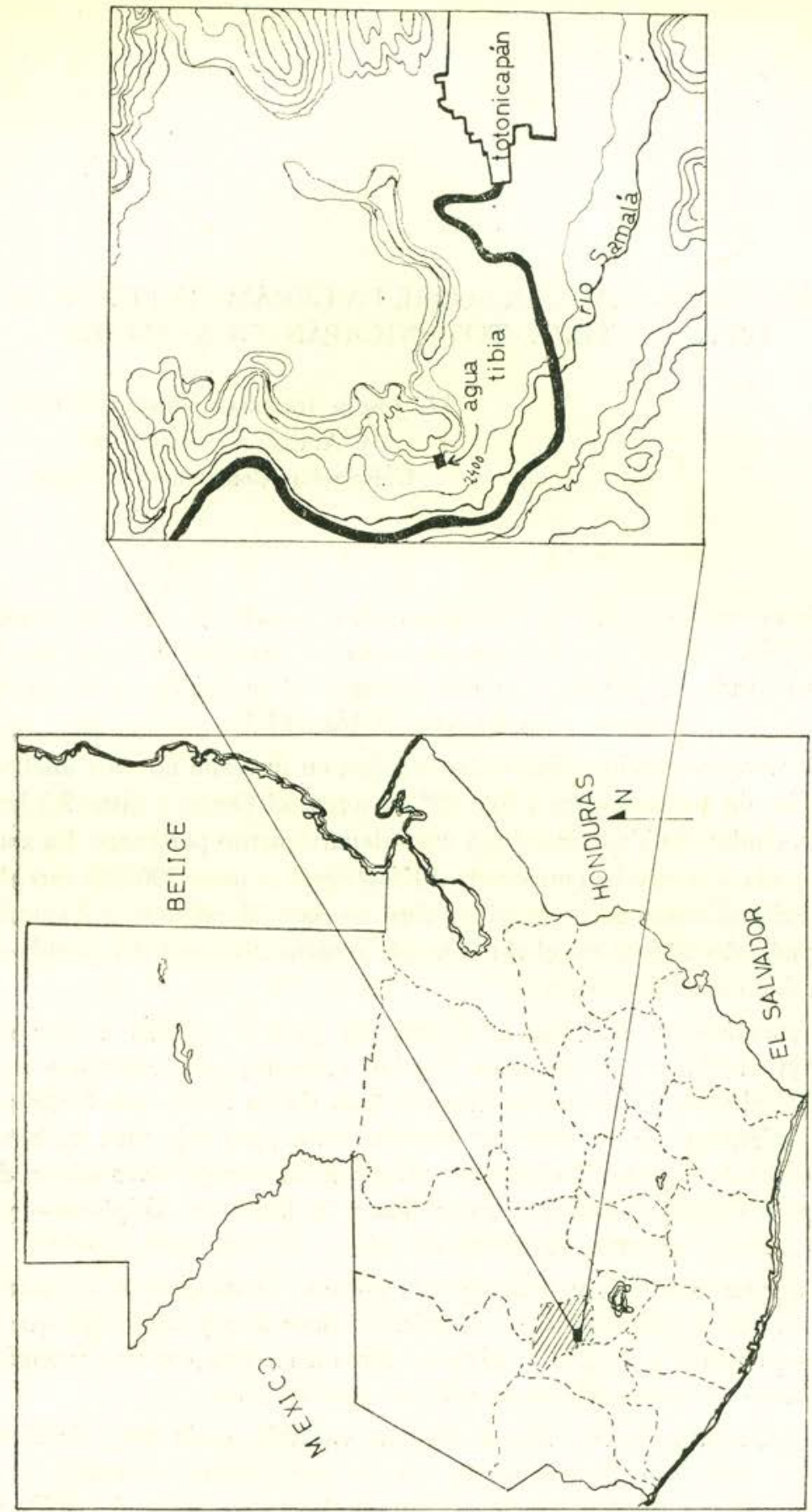

Fig. 1: Localización del asentamiento Agua Tibia, Totonicapán, Guatemala.

Estudios de Cultura Maya. Vol. XIII, 1981

Instituto de Investigaciones Filológicas/

Centro de Estudios Mayas, UNAM

http://www.iifilologicas.unam.mx/estculmaya/ 
una franja de habitabilidad con el fin de realizar un cálculo de población lo más exacto posible, así como la de verificar la presencia y función de algunos rasgos culturales que habían sido relevantes en la anterior excavación de Agua Tibia (Alcina, 1980).

El resultado ha sido el descubrimiento de un nuevo e importante elemento que complementa la visión de la unidad habitacional exi-. tente en el período Clásico Tardío a lo largo del valle de Totonicapán. Según esto, ya no habría dos franjas habitadas a lo ancho del cerro sino una, la cual se dispondría de la siguiente manera: en la parte más baja, y pegado a la zona de inundación del pequeño arroyo, se localizaría el basurero; en una banda intermedia - justo al final de la ladera- se situarían las demás unidades de habitación y demás servicios domésticos, tales como la casa y el temazcal, o artesanales como el horno; y en la parte inicial y media de las laderas, los enterramientos y otros rasgos de carácter sagrado.

Pero en lo que concierne al presente informe, sólo pretendemos dar a conocer una pequeña parte de los elementos culturales hallados en el cementerio: la cerámica funeraria. Baste pues decir que éste se encontraba en un área de 4.5 por $5.5 \mathrm{mts}$ y a $11.16 .5 \mathrm{mts}$ al Este de la casa y a unos $65 \mathrm{mts}$ del basurero.

Dado que la zona excavada se encuentra en un terreno que hasta hace dos años no se había comenzado a preparar para la siembra, los restos culturales se han mantenido sin que trabajos de roturación hayan podido avisar de su presencia y, por lo tanto, ser saqueados. No obstante, la existencia de pinos y sus gruesas raíces ha hecho que los vestigios se encuentren bastante removidos, hasta el punto de que algunos esqueletos se partieron por la mitad y fragmentos de cráneo aparecen distanciados casi un metro del cuerpo y su ofrenda.

El estado de éstos es, pues, bastante deficiente, y en un gran número de ocasiones tan sólo aparecen fragmentados restos de mandíbula o huesos largos, pero nunca partes lo suficientemente significativas como para saber por el momento la orientación, sexo, etc. Según hemos podido deducir, los enterramientos parecen haber sido efectuados en posición flexionada, con las piernas contraídas hacia el pecho y los brazos cruzados sobre ellas, característica muy común en otros localizados a lo largo del altiplano guatemalteco en tiempos del Clásico Tardío. Curiosamente no aparece ningún ejemplo de esqueleto en urna, hecho también frecuente para esta zona y período.

Con respecto a la orientación de los entierros, es poco lo que podemos decir, ya que prácticamente están situados hacia todas las direcciones, debido con toda seguridad a que fueron removidos y cambiados de lugar por la acción de las raíces. No obstante, parece ser que 
la orientación que prevaleció fue la N.NE, sin que las ofrendas parezcan tener un patrón especial en su colocación. En más de una ocasión el esqueleto fue sentado en un fragmento grande de metate o sobre medio apaste de considerable tamaño, el cual a su vez contenía una ofrenda. En cualquier caso, un estudio más en profundidad permitirá obtener nuevos datos al respecto.

Existe otra interrogante en cuanto a la disposición de los enterramientos que aún queda por esclarecer: la presencia de grandes losas de piedra bien cortadas, pero sin guardar una forma especial y que parecen estar íntimamente ligadas a éstos. Su función aún no está decidida (si se trata de marcadores de lugares sagrados, de un apoyo al enterramiento, etc.), pero han tenido los mismos efectos devastadores en la destrucción de los esqueletos que las raíces. Con todo, no existen tantas losas como entierros, sino tan sólo algunas, y no necesariamente están asociadas a aquéllos cuyo ajuar funerario es más rico.

\section{La cerámica funeraria}

Existe, por decirlo de alguna manera, una clara relación entre los tipos cerámicos encontrados en la casa y el basurero y los hallados en el recinto funerario recién excavado. Como es usual en ciertas ocasiones de la vida de una comunidad, los miembros de ésta se esforzaron en honrar a sus seres más allegados a la hora de su muerte. De esta manera, están representados en un sector muy pequeño del asentamiento una serie importante de cerámicas obtenidas por comercio, aunque sin duda alguna la cerámica autóctona es mayoritaria, presentando lo más fino de su producción.

\section{Cerámica Rojo sobre Crema}

Fortaleciendo una suposición particular que se gestó en el transcurso de las excavaciones de agosto de 1979 en Agua Tibia, la cerámica Rojo sobre Crema (que entonces alcanzaba un porcentaje del 12.6\% de un total de 29988 tiestos, y que constituía el segundo tipo mayoritario en el registro arqueológico) parece ser autóctona de la región comprendida entre Santa María Chiquimula y el valle de Totonicapán, ${ }^{1}$ dada la importancia del número y la variedad de dise-

1 Hasta ahora se ha venido pensando que la zona de origen de este tipo cerámico se encontraba en una región en torno a Zacualpa (Wauchope, 1975); sin embargo, ante la evidencia de un número muy superior de tiestos y de 
ños con que se presenta. Fundamentalmente, cuatro son las formas que han aparecido en el cementerio de Agua Tibia:

1. Cuencos de paredes curvas, boca ancha y bordes que varían de rectos a muy ligeramente dispuestos hacia el interior, que terminan en un labio redondeado. Las bases son convexas en todos los casos.

2. Cuencos de paredes y bordes rectos de labios redondeados. En ocasiones la pared se inclina un poco hacia el exterior. Bases planas a plano-convexas.

3. Cuencos de paredes evertidas y boca ancha. Los bordes son evertidos con labios redondeados. Bases planas.

4. Cuencos de silueta compuesta que se caracterizan por tener las paredes curvas desde la base, plano-convexa, hasta un punto de má. xima inflexión en que continúan rectas, disponiéndose ligeramente hacia el exterior. El borde es también recto, de labio redondeado.

Pero quizás no sea el número y la forma lo más importante en esta cerámica, sino la variedad del diseño con que está decorada y, sobre todo, el marcado contraste con la encontrada en el área del basurero o de la casa e incluso, aunque en una escala inferior con la del sector Y excavado en 1979. En efecto, si en estas zonas culturales el motivo decorativo más repetido y regular es el puramente geométrico — bien sea el de volutas, dobles y triples círculos concéntricos, fragmentos de figuras de pájaros y pares de líneas rojas y granates que se disponen en sentido vertical u horizontal, o la combinación entre algunos de ellos-, en el cementerio van a estar representados además una gran variedad de pájaros en actitudes diversas (fig. $2 a, b$ ), otros animales e, incluso, hombres representando una danza (fig. $2 \mathrm{c}$ y d). Tal vez sea éste el rasgo más importante en la decoración y diseño de la cerámica Rojo sobre Crema de los enterramientos: tales actitudes podrían estar indicando la existencia de un ritual y un culto funerarios que quizás alcanzarían su máxima expresión en la danza. A pesar de lo estilizado de los diseños, parece ser la idea de movimiento el rasgo artístico más representativo: de esta manera se explica que figuras como pájaros, una pulga en acción de saltar, un mono y hombres disfrazados en actitud de bailar (fig. 2d) estén integrados en el ajuar funerario. Al parecer, existe una evolución simbólica del diseño íntimamente relacionada con los entierros y con la idea de ultratumba que en otra ocasión trataremos de analizar.

Un rango que estimamos también muy importante y que aparece

una mayor sofisticación y variedad de diseños, pensamos que, al menos durante el periodo Clásico Tardío, algún lugar cercano al valle de Totonicapán fue el centro creador y difusor de esta cerámica. 
con una mayor frecuencia que en el resto de las zonas excavadas, es la decoración con pintura negativa, la cual adquiere también una considerable variedad de motivos: generalmente se dispone en forma de pequeños círculos que discurren en sentido horizontal (fig. 2e), colocándose entre los diseños de pintura roja, pero quizás sea más relevante la presencia de tréboles de cuatro hojas que alternan con la pintura y que parecen constituir la firma de un determinado alfarero. ${ }^{2}$ En ocasiones este motivo de pintura negativa no sólo se aloja en una franja horizontal de las paredes del cuenco, sino que se extiende hasta su base.

Un tercer rasgo que merece la pena resaltar es la relación entre diseño y forma:

A cuencos de paredes curvas corresponden fundamentalmente volutas que se disponen en distintas direcciones y círculos concéntricos asociados ambos a líneas o bandas verticales y horizontales de pintura roja (fig. 3a). En la mayoría de los casos está presente también la pintura negativa en forma de pequeños círculos. Excepción a la regla es la figura de un pájaro de bella factura que tiene sus alas extendidas, pero que parece aposentado (fig. 2a).

La forma más numerosa es los cuencos de paredes rectas que están decorados con los diseños más variados: así, a pájaros en clara actitud de vuelo se suman figuras con máscaras de mono $u$ hombre (fig. $2 \mathrm{~d}$ ) que guardan una disposición de danza y movimiento (fig. 3b). También aquí están representados dobles círculos y volutas verticales. El diseño de trébol de cuatro hojas con técnica de pintura negativa es frecuente en esta forma.

Los cuencos de paredes evertidas son más bien escasos y mantienen la misma tónica de decoración que la forma anterior.

Por último, a cuencos de silueta compuesta se asimilan motivos de dobles círculos concéntricos que se asocian a bandas y líneas de pintura roja dispuestas en sentido vertical y horizontal.

En resumen, parece existir una variedad formal y de diseño muy marcada, la cual está relacionada con el culto funerario que se manifiesta a través de la danza y el movimiento, actitud en que se encuentran la gran mayoría de los personajes representados en los cuencos.

2 Para una discusión más a fondo del origen y expansión de la pintura negativa en el altiplano de Guatemala véase Becquelin (1969) y Woodbury y Trik (1953). 


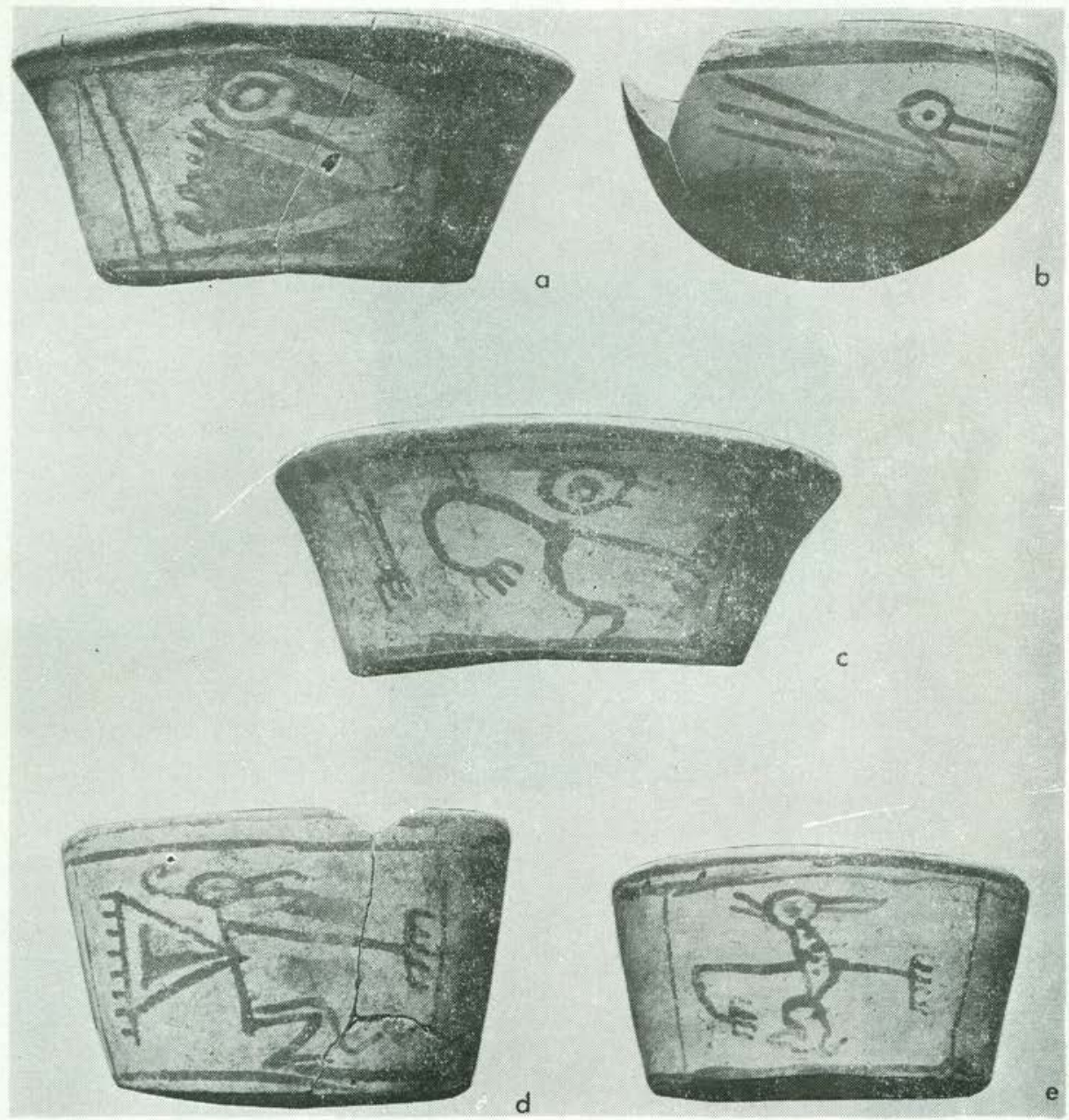

Fig. 2 a, b: Cucncos pertenecientes a la cerámica Rojo sobre Crema. Altura: $7 \mathrm{~cm}$ y $7.4 \mathrm{~cm}$.

Fig. 2 c: Cerámica Rojo sobre Crema, en la que se representa una figura h.rmann en actitud de danza. Altıra: $66 \mathrm{~cm}$

Fig. 2 d, e: Ccrámica Rojo sobre Crema, decorada con figuras humanas enmascaradas. Altura: 7.3 y $8 \mathrm{~cm}$, respectivamente.

Estudios de Cultura Maya. Vol. XIII, 1981

Instituto de Investigaciones Filológicas/

Centro de Estudios Mayas, UNAM

http://www.iifilologicas.unam.mx/estculmaya/ 


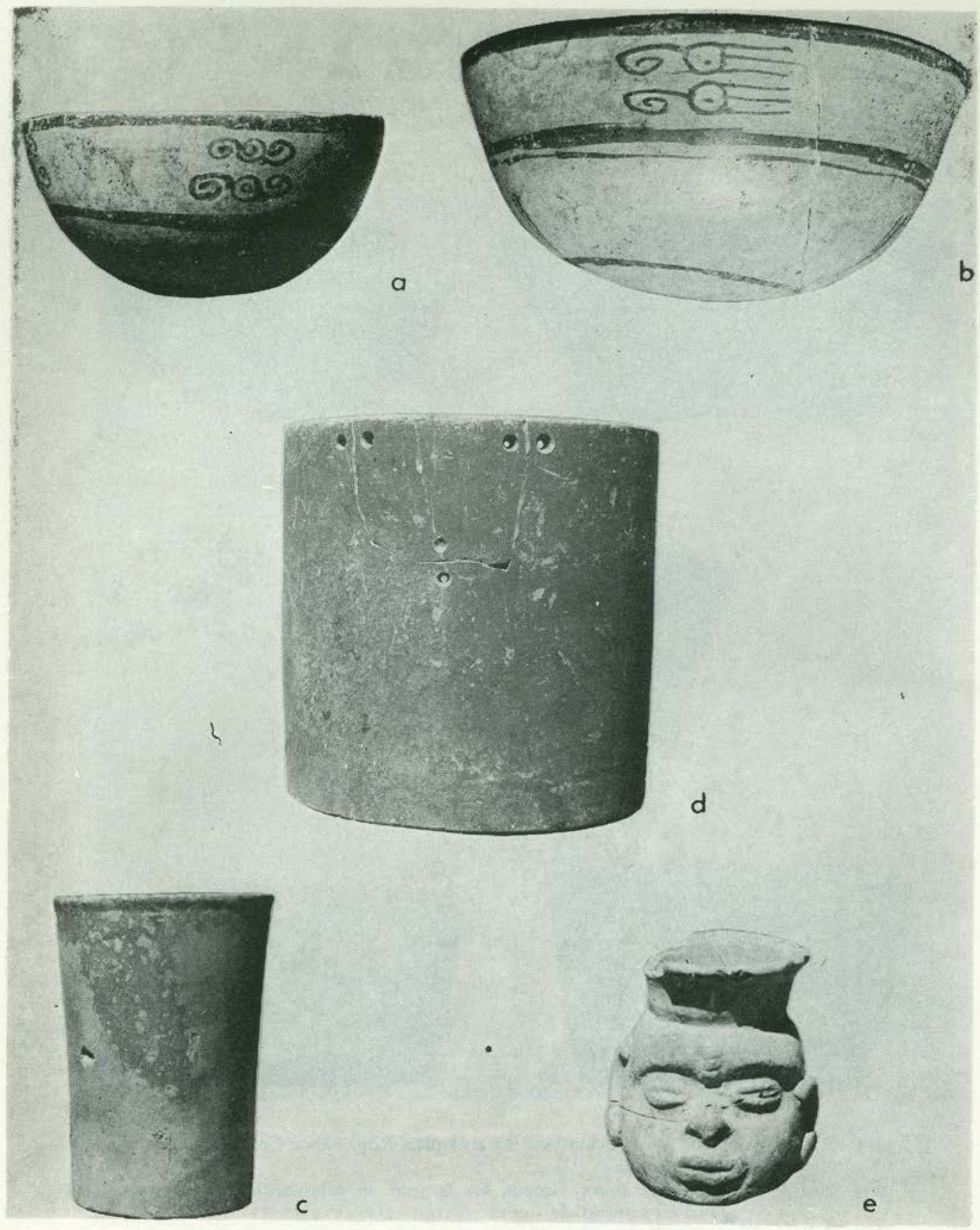

Fig. 3 a: Cerámica Rojo sobre Crema: círculos de pintura negativa alternan con volutas y dobles círculos concéntricos de pintura roja. Altura: $5.5 \mathrm{~cm}$.

Fig. 3 b: Cerámica Rojo sobre Crema. Cuenco con decoración geométrica muy estilizada. Altura: $7.3 \mathrm{~cm}$.

Fig. 3 c: Vaso de tipo San Juan Plomizo. Altura: $13.6 \mathrm{~cm}$.

Fig. $3 \mathrm{~d}$ : Vaso de cerámica Roja Fina: los agujeros parecen ser grapas que Estudios de Culturatalríán éplfragtnehê quebrado. Altura: $15.8 \mathrm{~cm}$. InstitutFige IB vestidániniatäälelfigieasde tipo Tiquisate. Altura: $6.8 \mathrm{~cm}$. Centro de Estudios Mayas, UNAM 


\section{Cerámica Estucada}

Este tipo cerámico es el segundo en importancia, rescatándose un total de siete ejemplares decorados con estuco. De ellos, seis se encontraban en muy mal estado, reduciéndose a fragmentos. La idea que se obtiene de éstos es que se trata de vasos semiprofundos de paredes rectas y bordes ligeramente evertidos que terminan en labios redondeados. Los engobes empleados en su decoración son muy finos, variando de negro a blanquecino, y estando en la mayoría de los casos muy erosionados.

Como es natural y ocurre en gran número de ocasiones, el estuco se había perdido incluso antes de ser descubiertos. A pesar de ello, siempre han quedado algunos restos de colores: verde, rojo, blanco, naranja y azul, aunque de ninguna manera se ha podido hasta ahora establecer el diseño decorativo.

\section{Cerámica Roja Ordinaria}

Los ejemplares pertenecientes a esta cerámica aparecen como contenedores de ofrendas, constituyendo uno de los tipos autóctonos del sitio. Sus formas tienen el denominador común de pertenecer al ajuar culinario y de uso cotidiano de los moradores del asentamiento, es decir que formas tales como incensarios cucharón o incensarios de doble cámara, que aparecen en la casa y en el basurero, no están en el enterramiento.

Las vasijas están cubiertas con un engobe muy fino, bien alisadas, y presentan zonas ennegrecidas por contacto directo con el fuego, ya sea en su superficie interna o en el exterior, debido a su utilización como contenedores de ofrendas.

Una de las formas más características la constituyen las vasijas zapato, una vieja tradición en el altiplano guatemalteco que en el contiguo valle de Quetzaltenango aparece ya en tiempos preclásicos. Apastes profundos de bordes reforzados, algunos de ellos disponiéndose hacia el interior, aparecen al menos entre el ajuar funerario de tres esqueletos, coincidiendo así con una de las formas más comunes extraídas en el basurero de la casa. Son también frecuentes los llamados comales, que más bien tienen formas de enormes cuencos hondos de borde recto y labio redondeado, y que están sostenidos por asas de sección cilíndrica u oval. Por último, elementos importantes de la cerámica funeraria de Agua Tibia son las vasijas con cuello de dos y cuatro asas, que tienen forma globular y base redondeada. 


\section{Cerámica Negra Pulida}

La presencia de este tipo en el registro arqueológico es importante. Se trata de una cerámica que ha sido engobada manteniendo unas tonalidades que oscilan de negro a anaranjado, plateado y marrón, características que parecen estar en relación directa con la cocción de los ejemplares. Por lo general, conservan un pulido muy fino, de tal modo que parecen guardar cierto paralelismo con la textura jabonosa tan común en las cerámicas negro-marrón, que tanto se extendieron en tiempos preclásicos y clásico tempranos en gran cantidad de sitios del altiplano guatemalteco y Chiapas. En este sentido, es posible que se trate de una evolución de la vieja tradición en la manufactura de cerámicas negro-marrón, la cual ha ido cambiando y adquiriendo nuevas formas y tonalidades según las modas impuestas en cada uno de los períodos. Dos formas son las representativas en esta cerámica: cuencos abiertos de paredes rectas a suavemente inclinadas hacia el exterior y base plana, que terminan en bordes rectos y labios redondeados; cuencos muy bajos de boca ancha, casi escudillas, con paredes curvadas hacia el exterior y labios redondeados. Se apoyan en una minúscula base anular.

\section{Cerámica San Juan Plomizo}

En principio, asociados a este tipo cerámico, que ha sido ampliamente discutido y descrito en un buen número de publicaciones (Thompson, 1948; Shepard, 1948; Lee, 1978), dos vasos profundos de paredes rectas a ligeramente curvas y bases planas. Su forma, engobe, color y otras características puramente externas nos inclinan a incluirlos dentro del tipo San Juan, aunque un análisis futuro más en profundidad ha de matizar tal suposición (fig. 3c). Vasos pro. fundos semejantes a éstos aparecen en gran parte de la contigua llanura costera y de la costa sur de Guatemala, así como en sitios semejantes de Chiapas, de los cuales uno de los más importantes parece ser Izapa.

Perteneciente también a la cerámica plomiza, se rescató una figurita hueca hecha en molde cuyos rasgos están bastante borrados, debido quizás a que el molde fue utilizado en exceso. En este caso, su filiación a la cerámica San Juan se nos antoja más difícil que en los mencionados vasos; en efecto, la inexistencia de ejemplos de figuritas de tipo San Juan contrasta con los conocidos de Tohil (Shook, 1965; 
fig. 4a) y, al igual que ocurre con los vasos, será necesario esperar un análisis de pastas para insertarla dentro de uno u otro.

\section{Cerámica Roja Fina}

Incluimos en esta categoría dos ejemplares que aún no han podido ser localizados en su contexto de origen, pero que, a nuestro parecer, provienen de algún sitio de la llanura costera cercano a Escuintla. Se trata de dos vasos medianamente profundos y anchos cuyo interior sólo ha sido alisado, mientras que la superficie externa aparece decorada con un grueso engobe rojo y después finamente pulida, manteniendo un suave tacto jabonoso. La base, plana, no ha sido engobada (fig. 3d).

En principio, pensamos que tales ejemplares pueden estar empa. rentados con las cerámicas decoradas con hematita especular tan co. munes en la zona de Escuintla, pero debemos esperar los resultados de un análisis más completo para poder clasificar esta cerámica.

\section{Cerámica Tiquisate}

Este tipo cerámico está representado únicamente por una vasija efigie, miniatura, que presenta un rostro humano de magnífica manufactura. Dos técnicas se alían en la confección de la efigie: el modelado, mediante el cual se han realizado los ojos, nariz y boca, y el pastillaje, que se empleó para colocar las orejeras que adornan esta figura humana (fig. 3e).

La forma de la vasija es globular de cuello medio y borde evertido que termina en un labio apuntado-redondeado y base plana. En general, podría estar formando parte del mismo contexto de miniaturas que se elaboraron a principios del Clásico Tardío en un área circun. dante a Escuintla.

\section{Cerámica Polícroma}

Dos fragmentos que forman parte de una vasija de silueta compuesta representan este tipo: se trata de una vasija de carena muy angulosa, con cuello y borde evertido y base convexa. Los colores empleados en su decoración han sido el rojo y negro sobre naranja, pareciendo formar un diseño de glifos cuya representación nos es de. 
conocida. La zona decorada se limita a la parte superior de las paredes, y se halla enmarcada por una banda de hematita especular que fue muy bien pulida.

Este tipo cerámico aparece asociado a tumbas en diversos sitios del altiplano Oeste y Norte, como es el caso de Zaculeu (Woodbury y Trik, 1953) y Nebaj (Smith y Kidder, 1951), y tiene su máxima expresión en Chamá (M. Butler, 1940), extendiéndose incluso hasta Chiapas (Ekholm, c. p.).

\section{Conclusiones}

En este pequeño informe se ha tratado de describir, de forma muy somera y en absoluto definitiva, una parte importante del ajuar funerario de un pequeño cementerio localizado en el altiplano Oeste de Guatemala. Aunque estimamos que un estudio realizado con más detenimiento, no sólo de la cerámica funeraria sino de todos y cada uno de los elementos culturales del sitio - el cual constituye el tema de tesis doctoral de uno de los autores- podrá completar un buen número de afirmaciones e hipótesis aquí planteadas, adelantamos una serie de características que darán una visión primaria de tal enterramiento:

1. Dado el número de esqueletos (19 en total) y su localización con respecto a la casa, parece tratarse de un enterramiento de tipo familiar, efectuado de manera similar a la practicada en ciertas comunidades del Oriente del país (Wisdom, 1961).

2. El sistema de entierros puede haber consistido en la excavación de hoyos en los que se colocó a los muertos en una posición flexionadosentada, casi fetal. En ocasiones, éste pudo haber sido reforzado con una losa de piedra bien cortada pero sin trabajar.

3. La orientación de los esqueletos está aún por determinar, aunque parece existir una cierta inclinación a colocarlos mirando hacia el N-NE.

4. Las ofrendas no nos han permitido hasta ahora establecer una distinción en cuanto al rango de los individuos, aunque un ulterior estudio puede aportar nuevos datos sobre este particular.

5. El conjunto cerámico anteriormente descrito está participando de un mismo contexto cultural de Clásico Tardío y formando parte de un desarrollo semejante al existente en otros sitios del altiplano y, en menor escala, en la costa Sur de Guatemala.

6. En el registro arqueológico de Agua Tibia existen dos grupos cerámicos en lo que respecta a su procedencia: tipos autóctonos, qu 
han sido creados en el mismo sitio o en los alrededores del mismo y foráneos, que se han conseguido mediante comercio. En este sentido, la cerámica Rojo Ordinario y Negro Pulido no parecen ser sino la evolución de tradiciones más antiguas de la zona, y están completamente adaptados e identificados con las formas y modas prevalecientes en el altiplano Oeste durante el periodo Clásico Tardío.

De la misma manera, podemos hablar de un tipo de cerámica, Rojo sobre Grema, cuya manufactura alcanza tal grado de sofisticación, variedad de diseños, $\mathrm{y}$ aparece en un número tan importante, que puede estar indicando la proximidad o presencia de su centro difusor. Pensamos que tal centro quizás se localice en los alrededores de Agua Tibia y no descartamos la idea de que se manufacturara en el horno excavado.

Esta especialización permitió la existencia de un comercio establecido en torno a tal actividad como producto primario, complementando quizás con el intercambio de otras mercancías que de manera más tradicional se venía efectuando desde más temprano. Este comercio tuvo probablemente dos vertientes: una de ámbito local, que en un análisis tan somero no es posible detectar ni describir, y otra de carácter regional, originando la formación de redes comerciales con otras comunidades del altiplano y con pueblos de la llanura costera y costa sur. En este sentido, cerámicas tales como las polícromas de tipo Chamá y los vasos estucados serían productos intercambiados con gentes procedentes del altiplano; mientras que los pertenecientes al tipo San Juan Plomizo, Tiquisate y Rojo Fino fueron conseguidos mediante el comercio con las comunidades costeras que en estos momentos del Clásico Tardío estaban produciendo tales artículos.

Así pues, Agua Tibia está participando de ese proceso de especialización local y regional que se desarrolló en la zona maya a lo largo de todo el periodo Clásico Tardío, y que tanto favoreció las relaciones comerciales, culturales y de diversa índole cuyo alcance, al menos en lo que se refiere al sitio en estudio, está aún por determinar.

\section{BIBLIOGRAFIA}

ALCINA Franch, José

1980 "Agua Tibia: un poblado Clásico Tardío en Totonicapán".

ms Antropología e Historia de Guatemala. Vol. 2; II Epoca. MiBecQuelin, Pierre nisterio de Educación. Guatemala, C. A. (en prensa).

1969 Archeologie de la Region de Nebaj (Guatemala). Institut d'Ethnologie. París. 
Butler, Mary

1940 "A pottery sequence from Alta Verapaz", The Maya and their Neighbors, ed. por Clarence L. Hay y otros; pp. 250-267. Dover Publications Inc., New York.

Lee, Thomas A., JR.

1978 "The origin and development of Plumbate pottery", Revista Mexicana de Estudios Antropológicos, Tomo XXIV, núm. 3,

Shepard, AnNa O. pp. 287-300. México.

1948 Plumbate, a Mesoamerican Trade Ware. Carnegie Institution of Washington, Pub. 573. Washington.

SHook, Edwin M.

1965 "Archaeological Survey of the Pacific Coast of Guatemala", Handbook of Middle American Indians, Vol. 2, Part 1, pp. 180-194. University of Texas Press. Austin.

Thompson, J. ERic S.

1948 An archaeological reconnaissance in the Cotzumalhuapa region, Escuintla, Guatemala. Contributions to American Anthropology and History, núm. 44. Carnegie Institution of Washington, Pub. 574. Washington.

WAUChOPE, ROBERT M.

1975 Zacualpa, El Quiché, Guatemala: An ancient provincial of the Highland Maya. Middle American Research Institute. Tulane

Wisdom, Charles University. New Orleans.

1961 Los Chortis de Guatemala. Seminario de Integración Social Guatemalteca, núm. 10. Guatemala, C. A.

Woodbury, Richard y Aubrey S. TriK

1953 The Ruins of Zaculeu, Guatemala, 2 Vols. Boston. 